\title{
THE WORLD REFERENCE LABORATORY FOR FOOT-AND-MOUTH DISEASE
}

\footnotetext{
$T$
} HE control of diseases of livestock is an important feature in the general economy of most countries in improving animal production and in fostering international trade in livestock and animal products. Foot-and-mouth disease is one of the most troublesome of the infectious diseases of livestock, and increasing attention is now being given on an international basis to its control and eradication.

It is gratifying to learn in this connexion that one of the recent steps taken, following negotiations between the Food and Agriculture Organization of the United Nations and the British Government, has been the establishment of a World Reference Laboratory for Foot-and-Mouth Disease at the Research Institute (Animal Virus Diseases), Pirbright, Surrey, which functions administratively under the ægis of the Agricultural Research Council.

It is particularly appropriate that the Pirbright Institute should have been asked to accept this responsibility because of its experience in the examination of virus material from all over the world during the past ten years and because it has all the necessary facilities for the full examination of suspect material.

The Institute reported recently the results of the examination and immunological classification of 2,200 virus samples from outbreaks in countries in Europe, Africa, Asia and the Americas. This must be considered only as a useful first contribution to a very big epizootiological problem as there are many areas which have not yet been covered. A satisfactory epizootiological world picture cannot be produced until a reasonably large number of samples have been examined from outbreaks in as many countries as possible. The Food and Agriculture Organization is seeking the co-operation of governments so that the surveys carried out for a number of countries will be continued and extended. It is hoped that one of the immediate results of this will be the continued collection and dispatch to the World Reference Laboratory, now established, of suitable field samples from outbreaks of the disease in countries all over the world.

The virus of foot-and-mouth disease, unlike those of yellow fever and rinderpest, is characterized by the lack of antigenic homogeneity. There are at present seven main immunological types of the virus (compared with three in poliomyelitis, three in influenza, three in equine encephalomyelitis and two in vesicular stomatitis). The well-known types $O, A$, and $C$ (1922-26) have been found in Europe, the Americas, Asia and Africa, and the work of the Pirbright Institute has brought to light four other types, three (S.A.T.1, S.A.T.2 and S.A.T.3) at present known only in Africa but one as far north as Egypt, and the fourth, $A S I A$ 1, only in Asia but as far west as Iran and Israel. It is possible that other types of the virus may be discovered as the result of more extended surveys. There are, in addition, strains of the virus within each main immunological group which differ sufficiently in antigenic constitution to classify them as variants or sub-types. Control programmes in many parts of the world include vaccination, and an essential to make these effective is accurate information on types and strain differences, so that appropriate vaccines can be used.

It is universally recognized that there is considerable advantage in having a central laboratory which is in a position to collect information on the distribution of virus types responsible for outbreaks, sporadic, enzootic and epizootic, and to complete surveys by collecting essential information on the character of outbreaks, the number and species of animals involved, the possible origin of outbreaks and other relevant details. The resulting epizootiological picture would be of much value in organizing methods of control and eradication and in assisting countries to estimate risks associated with trade. Reports of the world position will be issued through the Food and Agriculture Organization from time to time.

The functions of the World Reference Laboratory will include also the examination and classification of virus types and sub-types, the ultimate establishment of a collection of all types and confirmed sub-types and their corresponding antisera. It is not intended that the World Reference Laboratory should undertake the routine examination of virus material from European countries or the Americas, since there are already facilities for this purpose. The World Reference Laboratory will, however, give all possible assistance if specially requested to do so and will be assisting with the sub-type classification problem and be responsible for the examination and identification of strains of virus suspected to be other than types $O, A$, and $C$.

\section{THE NATIONAL VEGETABLE RESEARCH STATION}

\section{REPORT FOR 1956-57}

$\mathrm{T}$ HE eighth annual report* of the National Vegetable Research Station, recently published, provides a summary of the progress made by the eight sections of the Station. Some of our common vegetables are receiving the attention of the plant breeders, and further advance has been made in selecting a non-bolting type of red beet having singleseeded fruit. The production of onion and brussels

* British Society for the Promotion of Vegetable Research. Eighth Annual Report, 1957 (October 1956-September 1957). Pp. viii +67. Vegetable Research, 1958. sprout hybrids and a winter-hardy culinary pea is also being pursued. A report by L. E. Watts and R. A. T. George on a two-year investigation of the classification and performance of radishes involved the testing of 114 varieties made up of approximately equal numbers from British and foreign sources. An appendix to this report gives a classification and grouping of radish varieties. The authors conclude that there is no urgent need for a breeding programme for this vegetable as commercial varieties of satisfactory quality are already available. 